University of Nebraska - Lincoln

DigitalCommons@University of Nebraska - Lincoln

\title{
Evaluating spawning migration patterns and predicting spawning success of shovelnose sturgeon in the Lower Missouri River
}

M. L. Wildhaber

U.S. Geological Survey (USGS), mwildhaber@usgs.gov

S. H. Holan

University of Missouri - Columbia, holans@missouri.edu

G. M. Davis

University of Virginia

D. W. Gladish

University of Missouri - Columbia, dwg512@mail.missouri.edu

A. J. DeLonay

U.S. Geological Survey (USGS), adelonay@usgs.gov

See next page for additional authors

Follow this and additional works at: https://digitalcommons.unl.edu/usgsstaffpub

Wildhaber, M. L.; Holan, S. H.; Davis, G. M.; Gladish, D. W.; DeLonay, A. J.; Papoulias, Diana M.; and Sommerhauser, D. K., "Evaluating spawning migration patterns and predicting spawning success of shovelnose sturgeon in the Lower Missouri River" (2011). USGS Staff -- Published Research. 615. https://digitalcommons.unl.edu/usgsstaffpub/615

This Article is brought to you for free and open access by the US Geological Survey at DigitalCommons@University of Nebraska - Lincoln. It has been accepted for inclusion in USGS Staff -- Published Research by an authorized administrator of DigitalCommons@University of Nebraska - Lincoln. 
Authors

M. L. Wildhaber, S. H. Holan, G. M. Davis, D. W. Gladish, A. J. DeLonay, Diana M. Papoulias, and D. K. Sommerhauser

This article is available at DigitalCommons@University of Nebraska - Lincoln: https://digitalcommons.unl.edu/ usgsstaffpub/615 


\title{
Evaluating spawning migration patterns and predicting spawning success of shovelnose sturgeon in the Lower Missouri River
}

\author{
By M. L. Wildhaber ${ }^{1}$, S. H. Holan ${ }^{2}$, G. M. Davis ${ }^{3}$, D. W. Gladish ${ }^{2}$, A. J. DeLonay ${ }^{1}$, D. M. Papoulias ${ }^{1}$ and \\ D. K. Sommerhauser ${ }^{2}$ \\ ${ }^{1}$ U.S. Geological Survey (USGS), Columbia Environmental Research Center, Columbia, MI, USA; ${ }^{2}$ Department of Statistics, \\ University of Missouri - Columbia, Columbia, MI, USA; ${ }^{3}$ Department of Systems and Information Engineering, University of \\ Virginia, Charlottesville, VA, USA
}

\begin{abstract}
Summary
Approaches using telemetry, precise reproductive assessments, and surgically implanted data storage tags (DSTs) were used in combination with novel applications of analytical techniques for fish movement studies to describe patterns in migratory behavior and predict spawning success of gravid shovelnose sturgeon. From 2004 to 2007, over 300 gravid female shovelnose sturgeon (Scaphirhynchus platorynchus) from the Lower Missouri River, that were expected to spawn in the year they were collected, were surgically implanted with transmitters and archival DSTs. Functional cluster modeling of telemetry data from the spawning season suggested two common migration patterns of gravid female shovelnose sturgeon. Fish implanted from 958 to 1181 river kilometer ( $\mathrm{rkm})$ from the mouth of the Missouri River (or northern portion of the Lower Missouri River within $354 \mathrm{rkm}$ of the lowest Missouri River dam at rkm 1305) had one migration pattern. Of fish implanted from 209 to $402 \mathrm{rkm}$ from the mouth of the Missouri River (or southern portion of the Lower Missouri River), half demonstrated a movement pattern similar to the northern fish while the other half demonstrated a migration pattern that covered more of the river. There was no apparent difference in migration patterns between successful and unsuccessful spawners. Multiple hypotheses exist to explain differences in migratory patterns among fish from different river reaches. Additional work is required to determine if observed differences are due to multiple adapted strategies, environmental alteration, and / or initial tagging date. Hierarchical Bayesian modeling of DST data indicated that variation in depth usage patterns was consistently different between successful and unsuccessful spawners, as indicated by differences in likelihood of switching between high and low variability states. Analyses of DST data, and data collected at capture, were sufficient to predict 8 of 10 non-spawners / incomplete spawners and all 30 spawners in the absence of telemetry location data. Together, the results of these two separate analyses suggest that caution is necessary in extrapolating spawning success from broad-scale movement data alone. More direct measures of spawning success may be necessary to precisely determine spawning success and to evaluate the effects of management actions.
\end{abstract}

\section{Introduction}

Human activities that physically and chemically alter the riverine environment may have direct effects on spawning migration and success. This is a major concern for the
Missouri River where substantive physical changes have been made to support navigation, flood control, and power generation (Galat and Lipkin, 2000). These activities have been associated with the changes in the Missouri River native fish assemblage, most notably in the decline of shovelnose sturgeon (Scaphirhynchus platorynchus) and the listing of the pallid sturgeon (S. albus) as endangered (Funk and Robinson, 1974; Hesse and Sheets, 1993). Management activities (e.g., channel reconstruction and reservoir releases intended to naturalize the flow regime) have been initiated to benefit sturgeon in the Lower Missouri River (US Fish and Wildlife Service, 2000). Important information is lacking as to where, when, and under what conditions Scaphirhynchus sturgeon spawn, and their spawning success in the Lower Missouri River. This information is needed to design channel reconstruction and flow manipulations to promote reproduction and survival of young sturgeon. Despite extensive telemetry studies and sampling efforts, data sets for wide-ranging sturgeon species in large, open rivers often contain too few observations or have significant gaps between observations (e.g., Moser and Ross, 1995). Approaches and effective data analyses are needed which can elucidate distinct patterns of movement and predict spawning success with limited observational data.

The US Geological Survey initiated a limited telemetrybased study of sturgeon reproductive ecology in the spring of 2004 with gravid female shovelnose sturgeon to determine the range of spawning movements, the potential location of spawning sites, and whether or not reproductive females implanted with transmitters would spawn successfully (DeLonay et al., 2007b). Gravid females are in the late stages of reproductive maturation and are expected to spawn in the coming spawning season. Studies with shovelnose sturgeon were expanded in 2005-2007 to examine linkages between migration and spawning success and environmental variables. From a cursory examination of the telemetry data it appeared that all female shovelnose sturgeon exhibited a similar upstream spawning migration pattern and that spawning activity occurred at multiple locations throughout the Lower Missouri River (DeLonay et al., 2009). This research was unique in that it combined ultrasound, endoscopy, blood chemistry, histology, and high frequency recording of temperature and depth in data storage tags (DSTs) along with telemetry in monitoring the migration pattern and assessing spawning habitat of gravid shovelnose and pallid sturgeon. Ultrasound and endoscopy methods were used along with blood chemistry and histology assessments to verify sex and 
reproductive stage at implantation and at recapture of individuals after the spring and summer spawning season (Wildhaber et al., 2005, 2007).

One approach that can be used to explore patterns within and among datasets consisting of curves, is to use a functional clustering model (FCM) (James and Sugar, 2003 and references therein). Most traditional FCMs are designed for data that are sampled over a dense set of grid points. However, the sturgeon tracking data collected by DeLonay et al. (2007a) do not allow for the application of the traditional approach since fish were sampled sparsely (i.e., few relocations) and at different points in time. The method developed by James and Sugar (2003) provides for sparsely sampled data and allows for the borrowing of strength across curves to cluster curves in to like groups. In the case of fish, this technique allows modeling individual fish migration patterns over time. The application of FCMs to explore patterns of telemetry locations among fish from different locations in the river, and between successful and unsuccessful spawning fish, could provide insight into both adapted spawning strategies and impaired reproductive behaviors that may limit populations in altered environments.

A second approach for the analyses of sturgeon spawning migration and success was illustrated in preliminary research by DeLonay et al. (2007b). Changepoint analyses of continuously-recorded depth-usage data from DSTs implanted in migrating females indicated possible differences in depth-usage patterns between successful and unsuccessful spawning gravid shovelnose sturgeon. Follow-up research by Holan et al. (2009) with the DeLonay et al. (2007b) data indicated that successful spawning shovelnose sturgeon exhibit lower levels of variability in usage of different depths during the spawning season, compared to unsuccessful spawners. Regime switching, based on volatility, within a hierarchical Bayesian framework was used to predict spawning success, without the use of telemetry location data. Researchers hypothesized that the predictive capability of regime switching is a result of behavioral changes that occur just before, during and immediately after spawning. Specifically, successfully spawning shovelnose sturgeon appear to exhibit diminished variability in depth-use patterns, perhaps as a result of resting after rapid upstream migration to occupy spawning habitat and release eggs.

In this article, we use separate analyses of shovelnose sturgeon migration and depth-usage patterns to provide insights into shovelnose sturgeon reproductive behavior. We do this by examining the 2004-2006 tracking data from DeLonay et al. (2007a) to determine whether a common spawning migration pattern exists for gravid shovelnose sturgeon in the Lower Missouri River using cluster analyses for sparsely sampled functional data (James and Sugar, 2003). Additionally, we use new DST data collected from the tracking of additional gravid shovelnose sturgeon in the Lower Missouri River in 2007 to evaluate the effectiveness of the model developed by Holan et al. (2009) and provide more insight into differences in behavior of successful and unsuccessful spawning gravid female shovelnose sturgeon.

\section{Materials and methods}

From 2004 to 2007, 329 gravid shovelnose sturgeon were captured between March and April from the Lower Missouri River (Fig. 1) and implanted with ultrasonic transmitters and DSTs prior to spawning in late April through June (see DeLonay et al., 2007a,b for details). Thirty fish were captured between river kilometers (rkm, with river kilometers measured upstream from 0 at the Missouri River mouth to

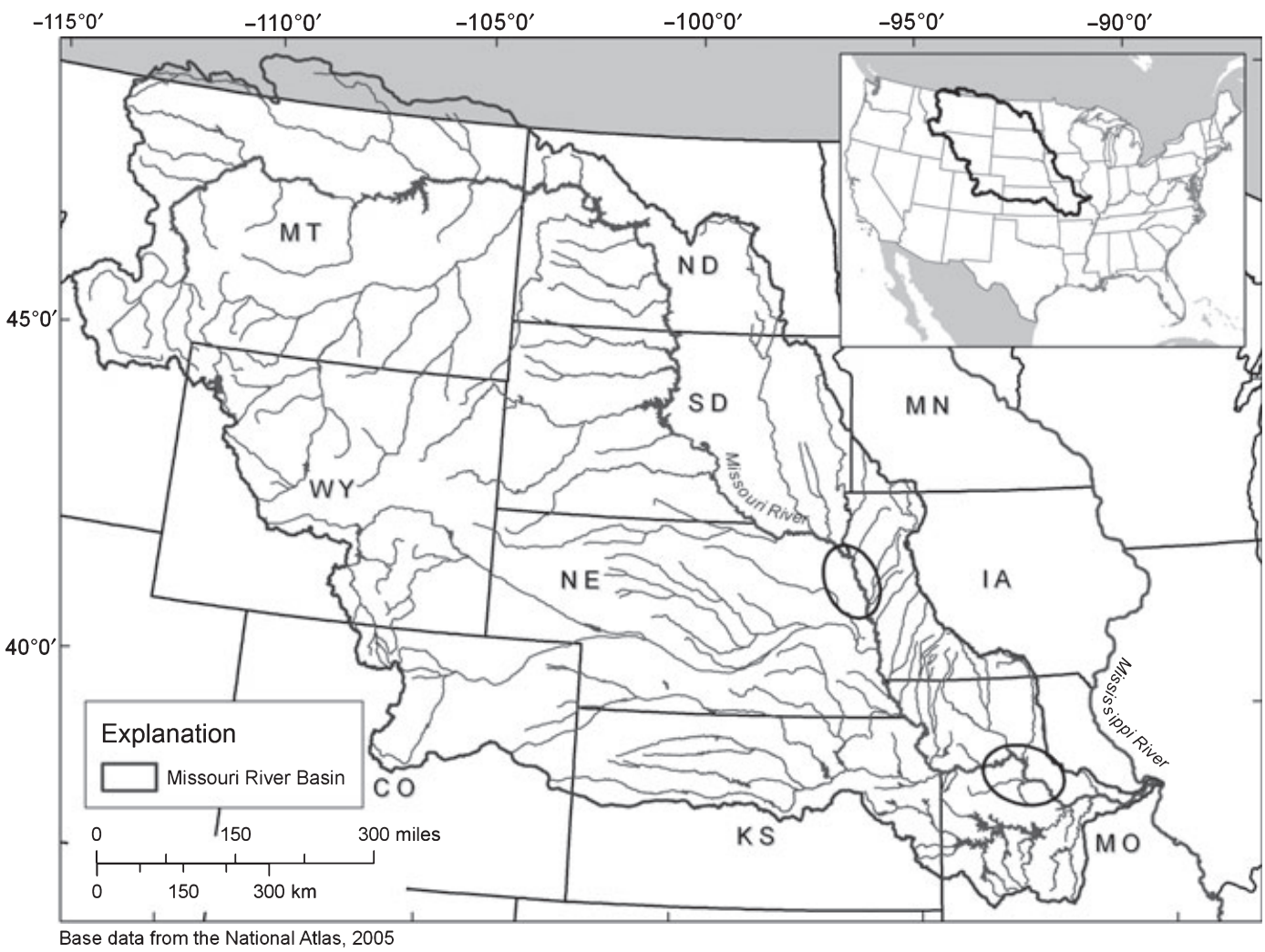

Fig. 1. Missouri River Basin and Lower Missouri River north and south sturgeon tagging areas (ovals). Northern fish implanted from 958 to $1181 \mathrm{rkm}$ from Missouri River mouth. Southern fish implanted from 209 to $402 \mathrm{rkm}$ from Missouri River mouth 
Gavins Point Dam at rkm 1297) 286 and 311 in 2004; 100 fish between 209 and 402 and 958 and 1181 in 2005; 100 fish between 209 and 402 and 958 and 1181 in 2006; and 99 fish between 1043 and 1217 in 2007. Each individual was weighed (g) and standard length $(\mathrm{mm})$ was recorded, gonads were visually inspected to verify reproductive stage, and blood and ovarian tissue were collected to determine readiness to spawn (see below). Blood was used to measure levels of 17 betaestradiol $\left(\mathrm{pg} \mathrm{ml}^{-1}\right)$, 11-ketotestosterone $\left(\mathrm{pg} \mathrm{m}^{-1}\right.$ ) and cortisol $\left(\mathrm{ng} \mathrm{ml} \mathrm{m}^{-1}\right.$ ) and ovarian tissue was used to measure the polarization index (PI). PI is the ratio of the distance from the germinal vesicle to the animal pole (i.e. the edge of the egg) relative to the distance from the animal pole to the vegetal pole; the lower the PI the closer the fish is to spawning. Gravid females $\geq 1 \mathrm{~kg}$ and with large black eggs, considered stage IV or greater (see Wildhaber et al., 2007), are expected to spawn that year. These fish were selected as candidates for implantation with ultrasonic telemetry transmitters and archival DST devices (Lotek Wireless, Inc., Newmarket, ON, Canada). Transmitter and DST weight did not exceed $3 \%$ of fish body weight to minimize instrumentation-related effects on behavior and reproductive maturation (Winter, 1996; Zale et al., 2005). Transmitters $(16 \times 65 \mathrm{~mm})$ had a battery life-expectancy of 9-14 months, individual identification recognition, minimum pulse intervals of $3500 \mathrm{~ms}$, and frequency of $77 \mathrm{kHz}$. Archival DSTs $(11 \times 32 \mathrm{~mm})$ recorded time, temperature, and pressure (i.e., depth) at least once every $15 \mathrm{~min}$. Fish were relocated during multiple, overlapping river sweeps that encompassed the entire $1305 \mathrm{rkm}$ of the Lower Missouri River. Throughout the next 5 months sturgeons were tagged and relocated at varying time points. At the end of the tracking seasons attempts were made to recapture each fish to assess whether or not it spawned and to download the DST data (11 of 28 fish in 2004, 18 of 87 fish in 2005, 21 of 78 fish in 2006, and 41 of 99 fish in 2007 were recaptured and had usable DST data). Several DSTs failed to record data and therefore numbers of recaptured fish may not equal the actual numbers of fish used in analyses.

Upon recapture, these shovelnose sturgeon were euthanized and necropsied to quantify spawning success. Spawning success was measured by the recapture oocyte ratio or spawning index (SI) which is the ratio of mature oocytes (eggs) to early stage oocytes as an indicator of the completeness of spawning. Lower ratios are indicative of more complete spawning. Classification of spawning success was based on the SI with $0 \leq \mathrm{SI} \leq 0.35$ considered a complete spawner (successful spawner) and SI > 0.35 considered an incomplete or nonspawner (unsuccessful spawner) (Holan et al., 2009). Of the shovelnose sturgeon recaptured with complete DST records, for 2004 4, 2005 3, 2006 3, and 200710 did not spawn.

\section{Analysis}

\section{Functional clustering of tracking data}

The FCM developed by James and Sugar (2003) was applied to the 2004-2006 shovelnose sturgeon tracking data to model individual fish migration patterns over time. To this end, we provide a brief overview of their approach. The description and notation we provide closely follows that of James and Sugar (2003, pp. 398-401).

Let $g_{i}(t)$ denote the true value for the $i$ th migration curve at time $t$, and let $\mathbf{g}_{\mathbf{i}}, \mathbf{Y}_{\mathbf{i}}$, and $\epsilon_{\mathbf{i}}$, respectively, denote the corresponding vectors of true values, observed values and measurement errors at times $t_{i l}, \ldots, t_{i n_{i}}$. Then the general functional model can be expressed as

$\mathbf{Y}_{\mathbf{i}}=\mathbf{g}_{\mathbf{i}}+\boldsymbol{\varepsilon}_{\mathbf{i}}, \quad i=1, \ldots, n$,

where $n$ is the number of sturgeon. It is assumed that the measurement errors, $\boldsymbol{\varepsilon}_{\mathbf{i}}$, have mean zero and are uncorrelated with themselves and with $\mathbf{g}_{\mathbf{i}}$. Additionally, it is assumed that any unobserved time points are missing at random. The modeling of $g_{i}(t)$ is accomplished using basis functions and, in particular, the method of James and Sugar (2003) makes use of natural smoothing splines as they require relatively few parametric assumptions. Specifically,

$g_{i}(t)=\mathbf{s}(t)^{\prime} \boldsymbol{\eta} \mathbf{i}$,

where $\mathbf{s}(t)$ is a $p$-dimensional spline basis vector and $\boldsymbol{\eta}_{\boldsymbol{i}}$ is a vector of spline coefficients that are modeled using a Gaussian distribution. In particular,

$\boldsymbol{\eta}_{\mathbf{i}}=\boldsymbol{\mu}_{\mathrm{z}_{\mathrm{i}}}+\boldsymbol{\gamma}_{\mathbf{i}}, \quad \gamma_{\mathbf{i}} \sim N(\mathbf{0}, \boldsymbol{\Gamma})$

where $\mathbf{z}_{\mathbf{i}}$ denotes the unknown cluster membership (cf. Eq. (4), James and Sugar, 2003). Parameterizing the cluster means further lets $\mu_{\mathbf{k}}$ be rewritten as

$\mu_{\mathrm{k}}=\lambda_{0}+\Lambda \alpha_{\mathrm{k}}$,

where $\lambda_{\mathbf{0}}$ and $\boldsymbol{\alpha}_{\mathbf{k}}$ are respectively $p$-dimensional and $h$-dimensional vectors, and $\boldsymbol{\Lambda}$ is a $p \times h$ matrix with $h \leq$ $\min (p, G-1)$, where $G$ is assumed to be the 'true' number of clusters from which the data are being sampled (see James and Sugar, 2003, for a comprehensive discussion). From here one can write the FCM as

$\mathbf{Y}_{\mathbf{i}}=\mathbf{S}_{\mathbf{i}}\left(\boldsymbol{\lambda}_{\mathbf{0}}+\boldsymbol{\Lambda} \boldsymbol{\alpha}_{\mathbf{z}_{\mathbf{i}}}+\boldsymbol{\gamma}_{\mathbf{i}}\right)+\boldsymbol{\varepsilon}_{\mathbf{i}}, i=1, \ldots, n$

$\boldsymbol{\varepsilon}_{i} \sim N(\mathbf{0}, \mathbf{R}), \quad \gamma_{i} \sim N(\mathbf{0}, \boldsymbol{\Gamma})$,

where $S_{i}=\left(s\left(t_{i \mathbf{1}}\right), \ldots, s\left(t_{\mathbf{i n}_{i}}\right)\right)^{\prime}$ is the spline basis matrix for the $i$ th migration curve. The choice of $\mathbf{R}=\sigma^{2} \mathbf{I}$ and a common $\mathbf{\Gamma}$ was made for all clusters due to the sparse data set we used for which a small number of parameters is advantageous (James and Sugar, 2003, p. 399).

To fit the FCM it is necessary to estimate $\lambda_{0}, \boldsymbol{\Lambda}, \boldsymbol{\alpha}_{k}, \boldsymbol{\Gamma}$, and $\alpha^{2}$. An iterative procedure was followed which first assigned a probability of belonging to a cluster to each sturgeon and then, given cluster assignments, the parameters are estimated and the process repeated. See Appendix A of James and Sugar (2003) for comprehensive details.

In order to solve for $\hat{\alpha}_{\mathbf{k}}$ one must first project $\mathbf{Y}_{\mathbf{i}}$ onto the $p$-dimensional spline basis to find

$\hat{\boldsymbol{\eta}}_{i}=\left(S_{i}^{\prime} \boldsymbol{\Sigma}_{i}^{-1} S_{i}\right)^{-1} S_{i}^{\prime} \boldsymbol{\Sigma}_{i}^{-1} \mathbf{Y}_{\mathbf{i}}$

Subsequently, $\hat{\boldsymbol{\eta}}_{\mathbf{i}}$ is projected onto the $h$-dimensional space spanned by the means $\boldsymbol{\mu}_{\mathbf{k}}$ to obtain $\boldsymbol{\lambda}_{\mathbf{0}}+\boldsymbol{\Lambda} \hat{\boldsymbol{\alpha}}_{\mathbf{i}_{0}}$ where

$\hat{\boldsymbol{\alpha}}_{i}=\left(\boldsymbol{\Lambda}^{\prime} S_{i}^{\prime} \boldsymbol{\Sigma}_{i}^{-1} S_{i} \boldsymbol{\Lambda}\right)^{-1} \boldsymbol{\Lambda}^{\prime} S_{i}^{\prime} \boldsymbol{\Sigma}_{i}^{-1} S_{i}\left(\hat{\boldsymbol{\eta}}_{\mathbf{i}}-\boldsymbol{\lambda}_{\mathbf{0}}\right)$.

The $h$-dimensional projection of $Y_{i}$ onto the mean space after centering is $\hat{\alpha}_{\mathbf{i}}$. Further, it can be shown that there is a direct relationship between the posterior probability of the $i$ th migration curve belonging to the $k$ th cluster and the squared distance between $\hat{\boldsymbol{\alpha}}_{\mathbf{i}}$ and $\boldsymbol{\alpha}_{\mathbf{k}}$ (Theorem 1 -James and Sugar, 2003). Estimation of parameters requires the use of an iterative procedure, in this case the expectation maximization algorithm. R code (R Development Core Team, 2009) for performing this algorithm was obtained from http://www-rcf.usc.edu/ gareth/. A complete discussion of this estimation approach can be found in Appendix A of James and Sugar (2003). 
Since the fish were collected at various locations throughout the river, prior to analyses, the set of observed locations for each sturgeon was 'standardized' to a zero river kilometer starting point. This was done by subtracting the individual sturgeon's collection point river kilometer from every river kilometer observation of that individual sturgeon. The goal was to prevent 'initial river kilometer' from being a confounder in determining sturgeon cluster assignment.

We utilized the FCM (James and Sugar, 2003) to create 2 and 3 clusters, based on sturgeon for which at least 2 and 4 data points were collected. This was done separately for all sturgeon combined and for all fish that were recaptured. Figure 2 presents the sturgeon movement curves before and after river kilometer 'standardization'. Note the time range of observations (ignoring year collected) spanned March 16-September 1. For ease of interpretation, time points were then labeled Day 1-Day 169. This presumes that, in general, the shape of the migration pattern is similar each year (i.e. there is no year effect). The validity of this assumption was assessed by examining FCMs in each year separately (unpublished data); similar results were found within each year. For the FCM analyses we looked at both results with two and three assumed clusters. We investigated the result of two cluster assignment for correspondence to northern vs southern fish or successful vs unsuccessful spawners. Northern fish were those implanted from 958 to $1181 \mathrm{rkm}$ from the mouth of the Missouri River (or northern portion of the Lower Missouri River within $354 \mathrm{rkm}$ of the lowest Missouri River dam at rkm 1305; Fig. 1). Southern fish were those implanted from 209 to $402 \mathrm{rkm}$ from the mouth of the Missouri River (or southern portion of the Lower Missouri River). For a three cluster assignment, we investigated a further breakdown of the data based on results from two cluster analyses (see Results).

\section{Hierarchical Bayesian Markov switching modeling of depth usage}

Holan et al. (2009) developed a hierarchical Bayesian model for predicting spawning success from DST data while retaining longitudinal depth variability information. The model includes univariate biological covariates as well as the longitudinal behavioral covariate of depth.
The model is used to predict the response variable referred to as 'logitratio' where logitratio $=\log \{r /(1-r)\}$ with $r$ denoting the recapture oocyte ratio as a measure of spawning success. Further, the model incorporates an eigenvalue predictor from the transition probability matrix in a two-state Markov switching model with generalized auto-regressive conditional heteroscedastic $(\mathrm{GARCH})$ dynamics as a generated regressor in a linear regression model.

Holan et al. (2009) observed that the probabilities for switching between regimes were higher for fish that had not spawned or had only partially spawned (i.e., unsuccessful spawner) (Fig. 3). They combined switching probabilities (i.e. from the high variability state to the low variability state or $p_{2 \mid 1}$ and from the low variability state to the high variability state or $p_{1 \mid 2}$ into a univariate measurement): the second eigenvalue of the probability transition matrix (i.e. $\left.1-p_{2 \mid 1}-p_{1 \mid 2}\right)$. The second eigenvalue for an unsuccessful spawner was lower than the second eigenvalue from a fish that completely spawned (i.e., successful spawner). Here we apply the Holan et al. (2009) approach originally developed for the 2004-2006 data to the 2007 data.

In 2007, there were 10 unsuccessful spawners and 30 successful spawners. Results are based on 10000 Markov chain Monte Carlo (MCMC) iterations (12 000 iterations discarding the first 2000 iterations for burn-in). Convergence of the MCMC algorithm was verified through visual inspection of the trace plots of the sample chains. Furthermore, all starting values, except $h_{i 1}$ (i.e., fish volatility), were chosen randomly from their respective prior distributions. The starting value of $h_{i 1}$ was set equal to the sample mean of fish depth (i.e., $d_{i t}$ ). See Holan et al. (2009) for a comprehensive discussion.

\section{Results}

\section{Functional clustering of tracking data}

Using two clusters and all fish with at least two observations, 142 fish were clustered into one group and 51 into the other (Figs 4 and 5). All northern fish and 59 southern fish were placed into the first group.

The lack of completely distinct north/south differences consistently emerged even when using more clusters and/or
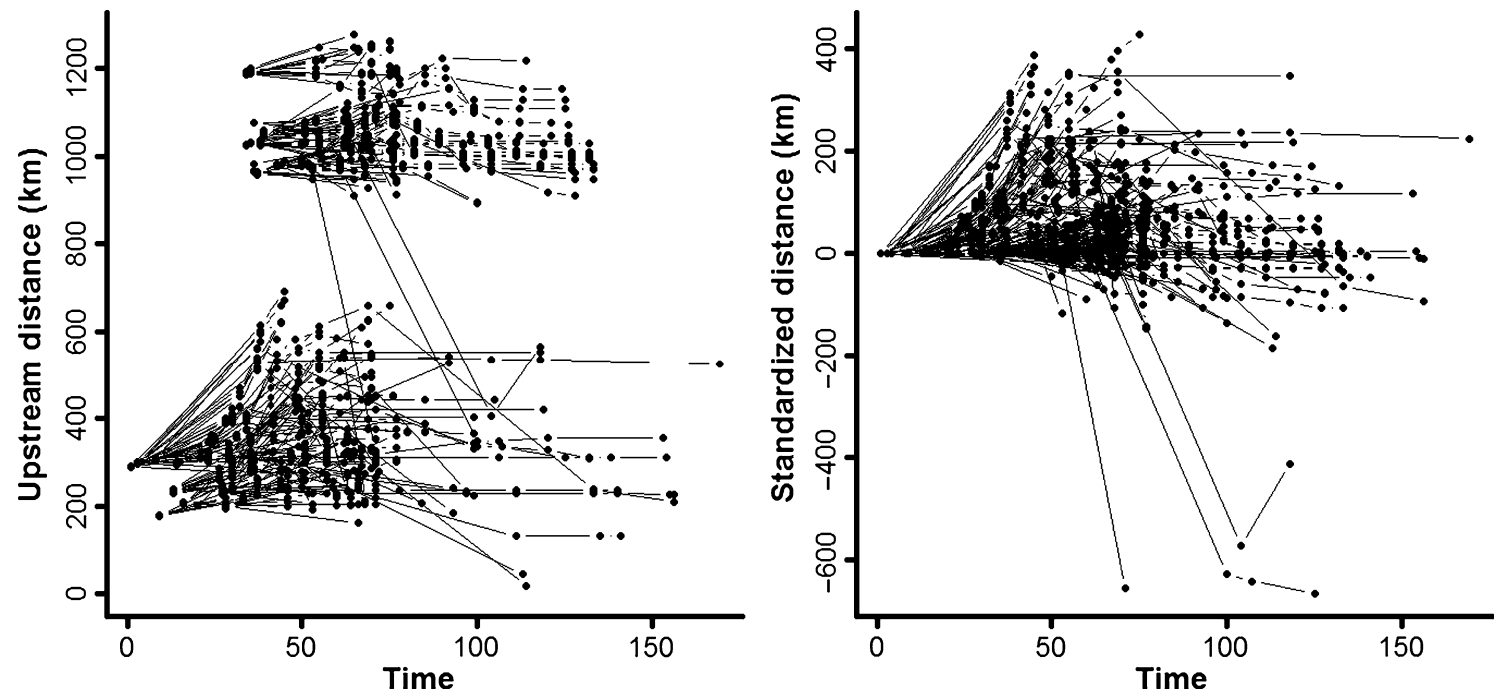

Fig. 2. Plots of the movement of all fish before (left) and after (right) standardization for river kilometers date of capture. Note that time is measured in days $1,2,3 \ldots$ starting with March 16 
Fig. 3. Sample tracking and data storage tag (DST) data from a spawner (top) and non-spawner (bottom) shovelnose sturgeon
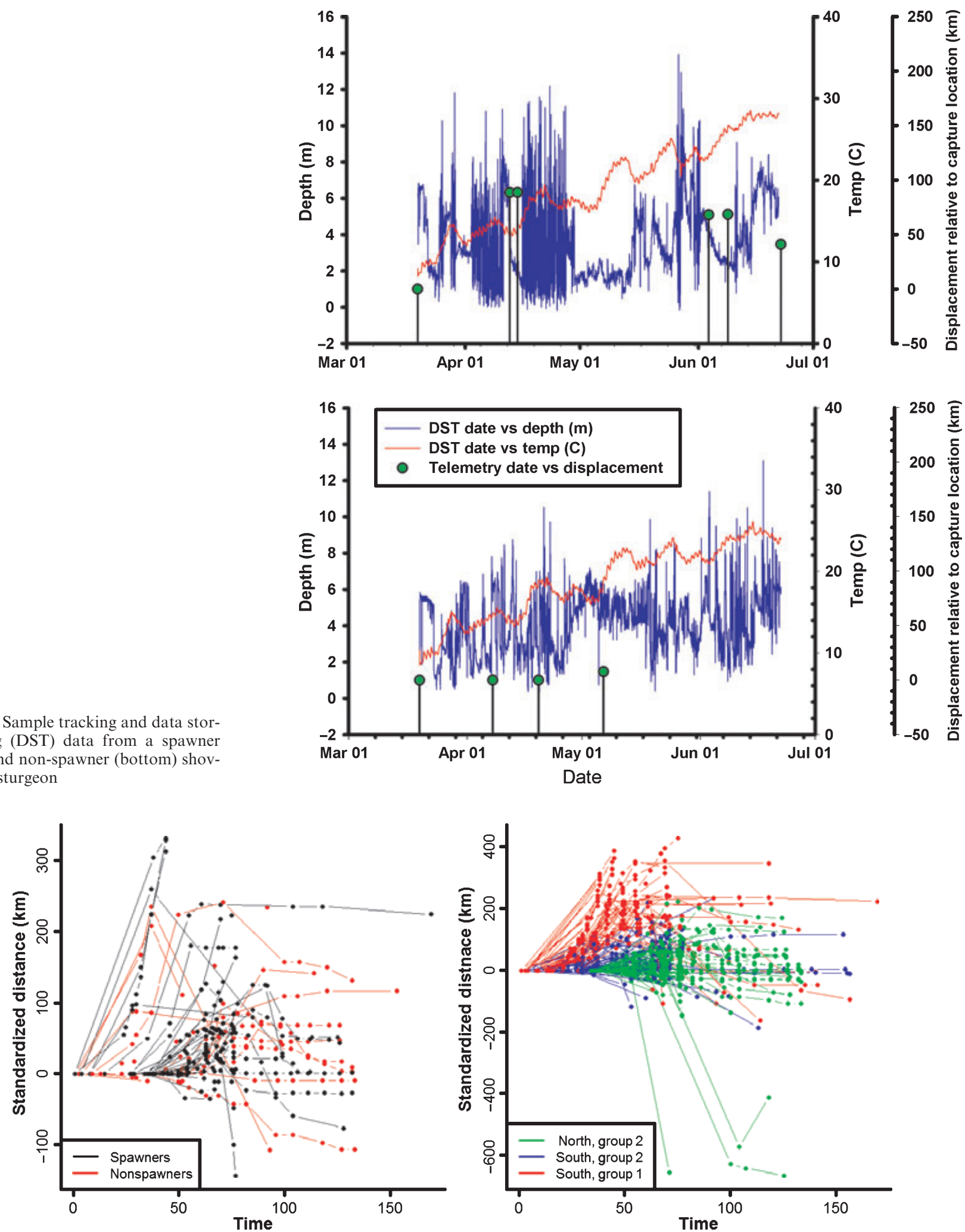

Fig. 4. Plots of the river kilometer-standardized movement of only those fish (left) with information on spawning (black is spawners, red is nonspawners) and fish (right) categorized by north or south and group 1 or group 2 . Northern fish implanted from 958 to 1181 rkm from Missouri River mouth (Fig. 1). Southern fish implanted from 209 to 402 rkm from Missouri River mouth. Note that time is measured in days 1 , 2, 3... starting with March 16

limiting analyses to fish with more than two observations. Using three clusters to see if there were one northern and two distinct southern groups, 75, 99, and 19 fish were distributed across the three groups with northern and southern fish in all three groups (Figs 4 and 5). For fish with at least four observations and using two clusters, 97 were clustered into one group and 42 into the other with all northern and 35 southern fish placed in one group. For three clusters, 8, 50, and 81 fish were distributed throughout the three groups with, again, northern and southern fish in all three groups. 

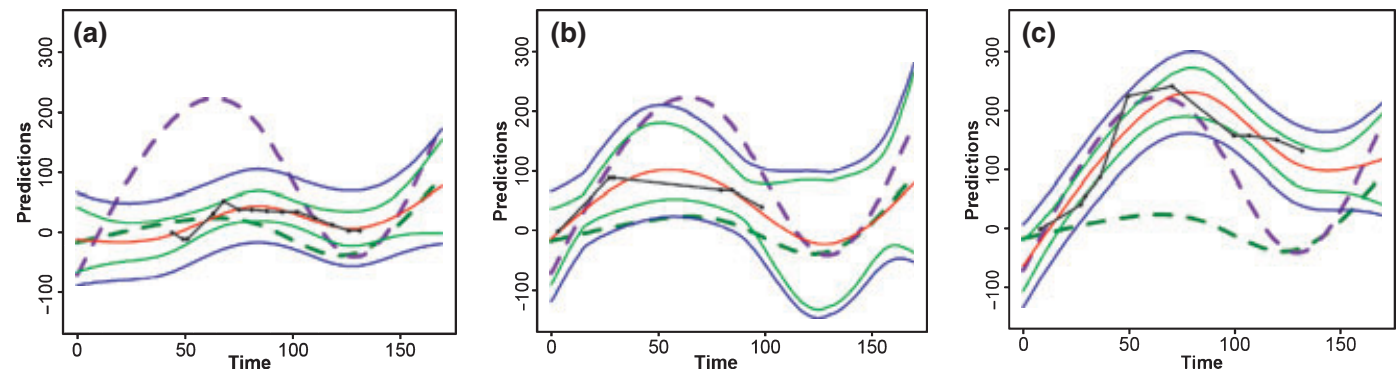

Fig. 5. Curves for three gravid female shovelnose sturgeon from clustering of 193. Northern fish implanted from 958 to $1181 \mathrm{rkm}$ from Missouri River mouth (Fig. 1). Southern fish implanted from 209 to $402 \mathrm{rkm}$ from Missouri River mouth. Southern group 2 fish (A); northern group 2 fish (B); and southern group 1 fish (C); black line observed data at dots; red line predicted curve at all time points purple and dark green dashed lines group 2 and 1 cluster means, respectively; and solid green and blue lines $95 \%$ confidence and prediction intervals, respectively. Note that time is measured in days $1,2,3 \ldots$ starting with March 16.
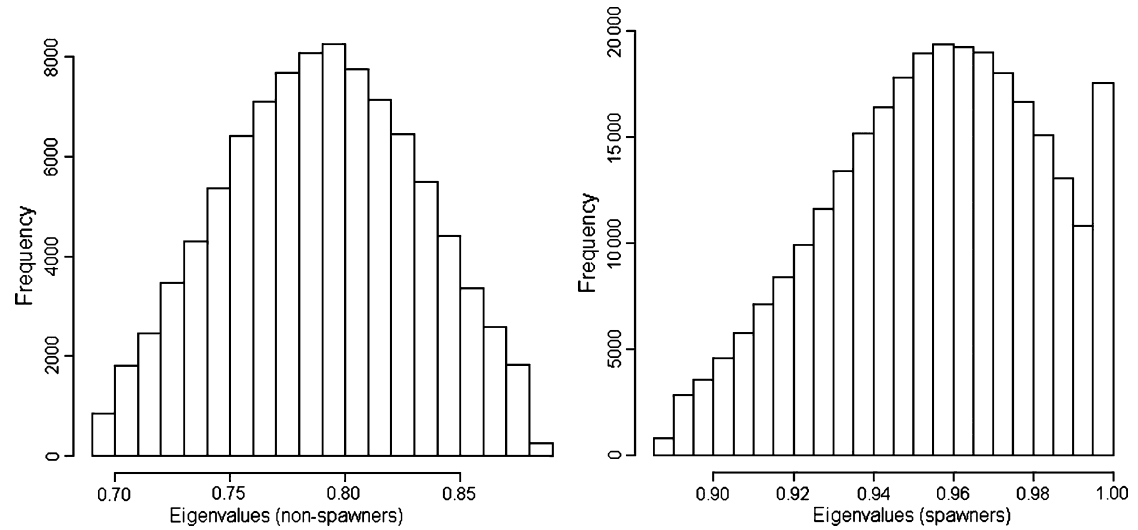

Fig. 6. Histograms of the posterior densities for the eigenvalue predictors (left plot) for all unsuccessful spawners and (right plot) for all successful spawners: note that these posterior densities are disjoint and have end points $(0.694,0.882)$ for the non-spawners and $(0.888,0.998)$ for the spawners

Since fish were only implanted with tags in the southern part of the river in 2004, we next considered fish from only 2005 and 2006 with two or more observations (i.e., 83 northern and 82 southern). Similar to the full data set, all northern fish clustered into in one group with southern fish split evenly between the two groups. Again, the three cluster analysis and the restriction of data to only fish with four or more observations provided no new information.

Since not all fish were recaptured to be re-evaluated for spawning success, we next considered only fish that had been recaptured and had two or more observations (i.e., 40 successful spawners and 10 unsuccessful spawners). Here nine unsuccessful spawners and 31 successful spawners were placed in one group with the rest placed in the second group.

\section{Hierachical Bayesian Markov switching modeling of depth usage}

As was seen for the 2004-2006 shovelnose sturgeon (Holan et al., 2009), the $95 \%$ credible interval (CI) of the eigenvalue predictor for non-spawners / incomplete spawners (0.6935878, 0.8817937 ) did not overlap the $95 \%$ CI of the eigenvalue predictor for successful spawners $(0.8884061,0.9980000)$ in 2007 (Fig. 6). Overall, the hierarchical model we developed, that included the eigenvalue predictor, was successful at identifying 8 of 10 non-spawners / incomplete spawners and all 30 spawners

\section{Discussion}

The FCM analysis of tracking data of gravid female shovelnose sturgeon that were expected to spawn during the period they were tracked indicated that movement curves were not distinctly different between fish implanted in the northern and southern study area or among successful and unsuccessful spawners. The primary result was that shovelnose sturgeon in the northern portion of the Lower Missouri River (i.e., 958-1181 rkm or within $354 \mathrm{rkm}$ of Gavins Point Dam) exhibited one consistent, shorter migration pattern, while there were approximately equal numbers of fish in the downstream study area (209-241 rkm from the mouth of the Missouri River) with short and long migration patterns. The consistency of these clusters of patterns is particularly striking given the limited number of observations for some individuals.

A number of hypotheses could be constructed to explain the apparent shortened migration of many northern females. Since tributaries to the Missouri River were not searched in 2004 2006 it is unknown to what extent shovelnose sturgeon may have used them for spawning. If northern shovelnose sturgeon made extensive use of tributaries for spawning in comparison to southern shovelnose sturgeon, it would appear from mainstem tracking data alone that the extent of their migration was shorter. Alternatively the presence of an upstream reservoir and the proximity to regulated flows may have altered environmental cues responsible for initiating early movements or encouraging long-distance migration as it does in other sturgeon species (e.g., Moser and Ross, 1995). Operation of the dam may have even influenced use of tributaries by shovelnose sturgeon by encouraging more individuals to attempt to spawn in them. Examination of telemetry locations in this study does not provide evidence that 
the upstream mainstem dam on the Missouri River served as a physical barrier to movement. The furthest upstream movement of any single reproductive female sturgeon was still several kilometers below the tailwaters of the dam. Further it is possible that shovelnose sturgeon may possess several migration strategies within the Missouri River. Some populations may adopt a long migration strategy, while others may migrate relatively short distances. While by no means exhaustive, the existence of differences in clusters between study areas is intriguing and merits closer study to determine if that difference is adaptive or the result of river management and habitat alteration. One complicating consideration when clustering groups of sturgeon based upon migration distances is the lack of certainty regarding where in their reproductive migratory trajectory individual fish were captured and implanted. Some of these fish were likely caught in late winter and earlier spring when they may have already migrated some distance which may be one reason for the shortened migration pattern observed in a number of the fish implanted in the southern portion of the study area.

Further validation and ultimate understanding of the observed shortened migration of northern and some southern females will require a research approach that addresses the questions of migration timing, tributary usage, differing populations, and reservoir management. Assessment of migration timing and the presence of differing populations require implantation of fish in the fall, prior to the start of their spring spawning migration and year-round tracking. Assessing tributary usage requires stationary telemetry receivers to determine when a fish enters a tributary and tracking within tributaries that are used. While determination of the influence of reservoir presence, river management, and habitat alteration requires multiple years of the level of tracking just described. Ultimately, it is of interest to combine the analyses from the FCM and DST model and to include environmental factors. In doing so, we hope to quantify the effect of the environmental factors on spawning behavior. Translating this idea into practical implementation and collecting the necessary data are areas for future research.

The lack of an observed difference in movement or 'spawning migration' patterns between successful and unsuccessful spawning gravid shovelnose sturgeon suggests that the observation of an upstream migration at a broad (100s of km) scale alone is not sufficient evidence to indicate that sturgeon are successfully spawning. The observation of upstream and downstream movements within the Klamath and Trinity Rivers, USA by green sturgeon (Acipenser medirostris) in the spring was used to characterize the spawning migration despite the fact that reproductive stage prior to implantation of tags and validation of successful spawning through visual observation and / or recapture never occurred (Benson et al., 2007). Moser and Ross (1995), who used the similar observations of upstream movement as evidence of spawning, were able to assess sex of obviously gravid female shortnose (A. brevirostrum) and Atlantic (A. oxrhynchus) sturgeon at implantation, but did not validate that successful spawning actually occurred. Again, with only validation of Gulf sturgeon spawning in the Pascagoula River Drainage, USA through egg collection (Heise et al., 2004) and spawning aggregations by lake sturgeon (A.fulvescns) (McKinley et al., 1998), researchers presumed that upstream migration and lack of upstream migration of reproductively mature fish alone differentiated successful and unsuccessful spawners, respectively. Our results support the idea that the conditions for documenting spawning success in sturgeon may be more complicated than previously assumed. Even if reproductively ready sturgeon exhibit the classically described behavior of upstream migration associated with spawning, an individual fish may never be exposed to the proximal conditions necessary for successful spawning to occur. Therefore, more direct measures of spawning success such as recapture of females or visual observation of spawning may be necessary to assess spawning success and evaluate the full effects of management actions.

Analyses of DST data from 2007 matched and validated the analyses performed with data from previous years and reported by Holan et al. (2009). Again the significance of the eigenvalue predictor lends support to the hypothesis that successful spawners exhibit lower levels of depth variability in their swimming pattern during the spawning season compared to unsuccessful spawners. Not only was the eigenvalue predictor significant, but also the $95 \%$ CI of the eigenvalue predictor for the successful and unsuccessful spawners did not overlap. This illustrates a clear separation between the two populations and supports the hypothesis that successful and unsuccessful spawners exhibit different behavioral patterns. The highly predictive nature of this model suggests that the success of spawning females can be predicted using DST data in the absence of telemetry location data, perhaps even years after the event.

Analysis of DST depth data found that, along with the eigenvalue for the transition probability matrix (previously described), weight at initial capture is a significant predictor of spawning success. Weight may be indicative of the fact that larger fish have a higher oocyte abundance and may tend to produce a less complete spawn.

This decreased variability of depth usage after successful spawning may also parallel the presumed post-spawning summer holding pattern observed in green sturgeon in the Klamath and Trinity Rivers (Benson et al., 2007). For the gravid Gulf sturgeon followed by Heise et al. (2004), the hypothetical depth use pattern of fish presumed to be non-spawners based on a shorter migration to a holding area would be the same migration and depth use patterns we observed for all the northern and similar southern successfully spawning shovelnose sturgeon. Therefore, caution may be needed when distinguishing spawning sturgeon based solely on the observation of a longer migration. Conversely DSTs may have broad applicability for other sturgeon species with characteristic migratory patterns, both in assessing spawning success and evaluating habitat use, once that pattern is well understood.

In our study, all fish were reproductively greater than stage IV when implanted so they were far enough along in the reproductive cycle to spawn during the study. Initial hormone levels and PI predictors provided no support for differences between successful and unsuccessful spawners in the DST model indicating these fish were at similar physiological states at the time of implantation. These last facts, along with the observed differences in depth-usage variability at a $15 \mathrm{~min}$ time scale between successful and unsuccessful spawners, support the premise that, even if a female shovelnose sturgeon is migrating and is physiologically ready to spawn, other, more proximal factors (e.g., environmental conditions experienced or presence of conspecifics) play a vital role in determining the spawning success of individual fish.

The FCM appeared to be effective at clustering movement patterns using individual sturgeon with as few as two location points; however, further validation of the results we observed 
would be helped by inclusion of larger numbers of fish with more observations per fish and by quantifying the uncertainty in cluster assignment. As previously alluded to, the value of the FCM and Markov switching models for understanding how management actions could affect spawning success of Lower Missouri River sturgeon could be enhanced by including environmental (e.g., temperature and flow) and biological condition (e.g., length, weight, hormones) in modeling movement curves. The inclusion of reproductive males and nonreproductive adults in tracking efforts may provide for a better assessment of the full range of variation in seasonal movement patterns and spawning migration strategies employed by shovelnose sturgeon in the Lower Missouri River.

\section{Acknowledgements}

This research was funded by the US Geological Survey and the US Army Corps of Engineers. We thank Janice Bryan and Kim Chojnacki (US Geological Survey) for their help with database management. Any use of trade, product, or firm names is for descriptive purposes only and does not imply endorsement by the U.S. Government.

\section{References}

Benson, R. L.; Turo, S.; McCovey, B. W., 2007: Migration and movement patterns of green sturgeon (Acipenser medirostris) in the Klamath and Trinity rivers, California, USA. Environ. Biol. Fishes 79(3-4), 269-279.

DeLonay, A. J.; Papoulias, D. M.; Wildhaber, M. L.; Mestl, G. E.; Everitt, D. W.; Chojnacki, K. A., 2007a: Movement, habitat use, and reproductive behavior of shovelnose sturgeon and pallid sturgeon in the Lower Missouri River. In: Factors Affecting the Reproduction, Recruitment, Habitat, and Population Dynamics of Pallid Sturgeon and Shovelnose Sturgeon in the Missouri River. C. E. Korschgen (Ed.). U.S. Geological Survey, Open-File Report 2007-1262, pp. 23-102.

DeLonay, A. J.; Papoulias, D. M.; Wildhaber, M. L.; Annis, M. L.; Bryan, J. L; Griffith, S. H.; Holan, S.; Tillit, D. E., 2007b: Evaluating Schaphirynchus spawning success: the use of behavioral and physiological indicators. J. Appl. Ichthyol. 22, 428-435

DeLonay, A. J.; Papoulias, D. M.; Jacobson, R. B.; Simpkins, D. G.; Wildhaber, M. L.; Reuter, T. M.; Bonnot, T. W.; Chojnacki, K. A.; Korschgen, C. E.; Mestl, G. E.; Mac, M. J., 2009 Ecological requirements of pallid sturgeon reproduction and recruitment in the Lower Missouri River - a research synthesis 2005-08: USGS, Scientific Investigation Report (SIR) 2009-5201, p. 91 .

Funk, J.; Robinson, J., 1974: Changes in the channel of the Lower Missouri River and effects on fish and wildlife. Missouri Department of Conservation, Jefferson City.
Galat, D.; Lipkin, R., 2000: Restoring ecological integrity of great rivers: historical hydrographs aid in defining reference conditions for the Missouri River. Hydrobiologia 422, 29-48.

Heise, R. J.; Slack, W. T.; Ross, S. T.; Dugo, M. A., 2004: Spawning and associated movement patterns of gulf sturgeon in the Pascagoula River Drainage, Mississippi. Trans. Am. Fish. Soc., 133, 221-230.

Hesse, L.; Sheets, W., 1993: The Missouri River hydrosystem. Fisheries 18, 5-14.

Holan, S. H.; Davis, G. M.; Wildhaber, M. L.; DeLonay, A. J Papoulias, D.M., 2009: Hierarchical Bayesian Markov switching models with application to predicting spawning success of shovelnose sturgeon. J. R. Stat. Soc. Ser. C 58, 47-64.

James, G.; Sugar, C., 2003: Clustering for sparsely sampled functional data. J. Am. Stat. Assoc. 98, 397-408.

McKinley, S.; Van Der Kraak, G.; Power, G., 1998: Seasonal migrations and reproductive patterns in the lake sturgeon, Acipenser fulvescens, in the vicinity of hydroelectric stations in northern Ontario. Environ. Biol. Fishes 51, 245-256.

Moser, M. L.; Ross, S. W., 1995: Habitat use and movements of shortnose and Atlantic sturgeons in the lower Cape Fear River, North Carolina. Trans. Am. Fish. Soc. 124, 225-234.

R Development Core Team, 2009: R: a language and environment for statistical computing. R Foundation for Statistical Computing, Vienna, Austria. ISBN 3-900051-07-0, http://www.R-project.org.

US Fish and Wildlife Service, 2000: Biological opinion on the operation of the Missouri River main stem reservoir system, operation and maintenance of the Missouri River Bank Stabilization and Navigation Project, and operation of the Kansas River reservoir system. US Fish and Wildlife Service, Bismarck.

Wildhaber, M. L.; Papoulias, D. M.; DeLonay, A. J.; Tillitt, D. E.; Bryan, J. B.; Annis, M. L.; Allert, J. A., 2005: Gender identification of shovelnose sturgeon using ultrasonic and endoscopic imagery and the application of the method to the pallid sturgeon. J. Fish Biol. 67, 114-132.

Wildhaber, M. L.; Papoulias, D. M.; DeLonay, A. J.; Tillitt, D. E.; Bryan, J. L.; Annis, M. L., 2007: Physical and hormonal examination of Missouri River shovelnose sturgeon reproductive stage: a reference guide. J. Appl. Ichthyol. 23, 382-401.

Winter, J., 1996: Advances in underwater biotelemetry. In: Fisheries Techniques (2nd edn) B. R., Murphy, D. W., Willis (Eds). American Fisheries Society Bethesda, Maryland, US, pp. 555590.

Zale, A. V.; Brooke, C.; Fraser, W. C., 2005: Effects of surgically implanted transmitter weights on growth and swimming stamina of small adult westslope cutthroat trout. Trans. Trans. Am. Fish. Soc. 134, 653-660.

Author's address: Mark L. Wildhaber, U.S. Geological Survey (USGS), Columbia Environmental Research Center, 4200 New Haven Road, Columbia, MI 65201, USA.

E-mail: mwildhaber@usgs.gov 